\title{
The Law and Incomplete Database Information as Confounders in Epidemiologic Research on Occupational Injuries and IIInesses
}

\author{
Arthur Oleinick, MD, JD, $\mathrm{MPH}^{1} *$ and Brian Zaidman, $\mathrm{BA}^{2 \dagger}$
}

\begin{abstract}
Background Capture-recapture studies report undercounting of work injuries/illnesses with days away from work (DAFW) in the Bureau of Labor Statistics annual Survey of Occupational Injuries and Illnesses (BLS SOII) by 25-68\% depending on the state and undercounting by various state workers' compensation (WC) systems of eligible claims by $5-35 \%$.

Methods Statutory/regulatory criteria defining eligible cases are used to adjust counts in the 1998-2001 Minnesota's WC system and the BLS SOII to permit comparison and to evaluate the recent studies. Missing information in the employer database used in the capture-recapture studies is tabulated. An attempt is made to harmonize results with two additional databases counting work injuries.

Results Counts in the BLS SOII moderately undercount by 10-16\% the number of WC cases. We believe that matching in capture-recapture studies is adversely affected by misperceptions regarding the application of statutory/regulatory eligibility criteria and by missing data. The result is that the reported undercounts in both the BLS SOII and several state WC databases are overstated in the capture-recapture studies. Although three offour databases can be approximately harmonized, the fourth cannot.

Conclusions More precisely targeted information is needed before decisions regarding redesign of the BLS survey are made or before legislative or administrative changes in the WC are contemplated. Am. J. Ind. Med. 53:23-36, 2010. ๑ 2009 Wiley-Liss, Inc.
\end{abstract}

KEY WORDS: occupational accidents; epidemiologic methods; capture-recapture; surveillance

\footnotetext{
${ }^{1}$ Environmental Health Sciences, School of Public Health, University of Michigan, Ann Arbor, Michigan

${ }^{2}$ Policy Development, Research and Statistics, Department of Labor and Industry, State of Minnesota, St. Paul, Minnesota

The views expressed in this article are those of the authors and do not reflect official policy or position of the Department of Labor and Industry, State of Minnesota.

†Senior Research Analyst.

*Correspondence to: Arthur Oleinick, Associate Professor Emeritus, Environmental Health Sciences, School of Public Health, University of Michigan, Ann Arbor, Ml 48109.

E-mail: aoleinic@umich.edu

Accepted 3 September 2009

DOl 10.1002/ajim.20763. Published online in Wiley InterScience

(www.interscience.wiley.com)
}

\section{INTRODUCTION}

Few epidemiologists, it seems safe to say, have had the need or occasion to consider the law as a confounding variable in the design of their studies. However, in the special case of studies intended to evaluate the performance of social legislation such as the Occupational Safety and Health Act (OSHA) or workers' compensation (WC) laws, determination of the sensitivity of case ascertainment of eligible cases is crucially dependent on the law's definition of eligible cases. Three recent studies [Oleinick and Zaidman, 2004; Rosenman et al., 2006; Boden and Ozonoff, 2008] that have attempted to reconcile case ascertainment by these federal and state schemes have reported widely differing results. In this update and expansion of our earlier article, we attempt to show that the differences, to a large extent, reflect differences 
In the text that follows, the following abbreviations are used and are presented here for convenient reference:

DAFW = days away from work, not including day of injury in various study periods.

DBA $=$ Doing Business As, a name that identifies a company with a legal or corporate name and is often called a trade name.

$\mathrm{EN}=$ establishment number, a unique number assigned to each separate unit in the legal entity for an employer and appended to the UI number. It is the basic sampling unit for the annual BLS survey.

FEIN $=$ federal employer identification number, a unique number assigned to each employer for tax purposes by the Internal Revenue Service.

$\mathrm{LDB}=$ Longitudinal Data Base used by BLS to draw the sample for the annual survey. It is obtained from the BLS Division of Covered Employment and Wages, the unit responsible for the national unemployment insurance database.

NHIS = National Health Interview Survey, conducted by the federal National Center for Health Statistics.

NIESS = National Electronic Injury Surveillance System, developed by the federal Consumer Product Safety Commission and supported by the National.

OSHA = Occupational Safety and Health Administration.

PPD = permanent partial disability, payments for permanent loss of some degree of ability to work or loss of a percent of body function, paid after or in addition to the period of temporary disability.

PTD $=$ permanent total disability, generally a classification reflecting an inability to work.

$\mathrm{TPD}=$ temporary partial disability, payments for partial days away from work (light duty at a lower wage, reduced hours on the job).

TTD $=$ temporary total disability, requires full days away from work.

$\mathrm{UI}=$ unique unemployment insurance number assigned by each state and transferred to the BLS Longitudinal Data Base.

$\mathrm{WC}=$ workers' compensation.

N.B. The definitions of legal terms are simplified and do not take into account the nuanced variations imposed by statute and court decisions.

in the treatment of the law as a confounder in the various study designs and, to a lesser extent, may also reflect missing data in databases used for matching in the two capturerecapture studies [Rosenman et al., 2006; Boden and Ozonoff, 2008].
Both the BLS' annual Survey of Occupational Injuries and Illnesses (SOII) (http://www.bls.gov/iif/home.htm) mandated under OSHA [29 USC, 2000a suppl 5] and state WC systems are intended to ascertain occupational injuries and illnesses. Except for cases without any medical costs and/ or without a minimum number of days of work disability (not in the WC files) or cases not meeting OSHA's record-keeping requirements [29 CFR, 2008] (not in the SOII), occupational injuries or illnesses should be recorded in both databases. However, laws and regulations (WC) and survey design (SOII) further subdivide each of these databases so that no pairing of the resulting subsets from each database is directly comparable without further adjustment. The failure to adjust each of the comparison subsets results in misidentification of non-matches that throw off the sensitivity analysis by producing "false-positive" candidates for matching [Brenner, 1996].

The three data subsets in the SOII are the group of cases with complete DAFW (not counting the day of injury or nonscheduled time such as weekends through 2002) [BLS, 2000], the restricted work group and the group with medical care as a result of the injury or illness but without time away from work in the form of DAFW or restricted worktime. Case-specific data are obtained for only a sample of cases with one or more DAFW and then extrapolated for national and state estimates. Only summary estimates are obtained for the two other groups of work injuries. In contrast, detailed information is potentially available on all cases ascertained by WC systems because the data are collected to determine eligibility for coverage, although some states may not collect complete information on medical payment only cases from the insurance companies that process the claims. The WC cases receiving wage compensation for time away from work must generally exceed some minimum interval and are then subdivided into payment groups reflecting the type of work disability produced by the work injury or illness.

Since case-specific information is available only for DAFW cases and wage compensation cases in many WC jurisdictions, investigators have focused on comparison of SOII cases with DAFW and WC cases eligible for wage compensation on the basis of days of disability. Capturerecapture methodology, with its ability to estimate cases not found in either database [Jansson et al., 2005], requires casespecific information and is necessarily restricted to a comparison of WC wage compensation cases and the SOII DAFW subset. However, the problem with any direct comparison between subsets in the two databases is the SOII's reliance on full DAFW prior to 2002, excluding nonscheduled time, compared to WC's use of calendar days of work disability, including non-scheduled time so long as other conditions are met.

In view of the substantial discrepancy between the three studies that attempted to reconcile these two databases, we decided to update our report by including Minnesota data for 
2001 so that statewide counts for the same period of 1998 2001 could be more easily compared between the Boden and Ozonoff [2008] and Oleinick and Zaidman [2004] studies. In evaluating the Michigan study, we also used results from a study of the 1986 Michigan WC system [Oleinick et al., 1991] since the legal system and practices had not changed in relevant part between the two time periods involved. Our analysis strongly suggests that there is some undercount of DAFW cases by BLS and that the two capture-recapture studies' sensitivity estimates are too low. In part, this appears to be the result of underestimating the impact of the 3-day calendar waiting period imposed by Minnesota statutes [Minn. Stat., 2007a] and the 7-day waiting period convention in Michigan statutes [Mich. Comp. Laws, 2008a,b] and, in the case of Michigan, by the inclusion of claim forms that probably did not actually qualify as claims. It may also reflect missing data in the databases used to match cases in the capture-recapture analyses. The difference in the results of the three studies provides an opportunity to consider how the precise legal eligibility requirements affect study design and to consider how other structural differences in the databases may cause problems in matching.

\section{METHODS}

\section{Legal Issues}

The methods used to prepare the original table are fully described in the earlier report [Oleinick and Zaidman, 2004] and are summarized here. Our aim was to compare statewide counts (WC) and estimates (SOII) using data that was adjusted to insure comparability. In brief, we obtained individual year SOII DAFW distributions for Minnesota for 1998-2001 from the BLS. We retained counts from state and local governments $(\sim 11-12 \%$ of the total) in both counts because, while these two industry groups are reported separately by SOII, the ownership codes used to identify government establishments do not always clearly identify comparable cases in the WC database.

In addition, we retained case counts for $\sim 5,200$ SOII cases ( $\sim 4.6 \%$ of the final total) over the 4 -year period where the SOII identified cases by means of sources other than the sample (mining and railroad companies), or where the company responsible for the SOII report might differ between the two data sets (temporary employment agencies and membership organizations). Cases from these industries were covered by the WC system. In addition, the few cases from the water transportation industry were retained in the SOII count although compensation cases in this area are often covered by the federal Longshore and Harbor Workers' Act [33 US Code, 2000b suppl 5]. In this article as well as in the earlier article, we excluded 160 cases/ year from farms with fewer than 11 employees from the WC count since the SOII does not cover this group. All eight industries noted, including local and state government, were excluded from the Boden and Ozonoff [2008] case-specific comparison.

From the BLS totals for each year, we subtracted the estimated number of cases with $\leq 3$ DAFW to insure that the remaining cases would all have been eligible for wage compensation under the calendar counting convention. As the BLS provides counts of cases with 1,2, and 3-5 DAFW, we had to estimate the number of SOII cases with 3 DAFW and did so by either dividing the number for the 3-5 DAFW period by three or by assuming that the percent decrease in cases between the first and second DAFW was applicable to the decline between the second and third day. The result is a range estimate. A precise estimate of the number with 3 DAFW was not an option because BLS would have had to reestimate survey weights.

To adjust for having subtracted all cases with $\leq 3$ DAFW in the BLS group, we subtracted from the WC group all those cases whose missed workday payments were based on $\leq 3$ DAFW (in fact, there are at least 11 scenarios that qualify for wage indemnification with this criterion and result in payments for temporary total disability (TTD) of $\leq 3$ days). Further, in including wage compensation cases, we used only those cases that received TTD ( $83-85 \%$ of cases) because such payments reflect DAFW and cases with permanent total disability (PTD) $(0.1 \%$ of claims) payments because the grievous nature of the injury in this latter group assures that such affected workers meet the calendar day waiting period requirement [Minn. Stat., 2007b].

The complex relation between DAFW in the BLS system and calendar counting requirements in the Minnesota WC system is illustrated by two examples. A worker injured on Monday finishes her/his shift, stays off work Tuesday through Thursday (3 DAFW) and returns to work Friday (in our earlier study about one third of injured workers left work on the day of injury) [Oleinick and Zaidman, 2004]. No wage compensation is due because the 3-day calendar waiting period begins on the first day of absence from work [Minn. Stat., 2007a]. However, a worker who is injured on Friday and leaves work to receive medical care, is not scheduled to work on the weekend and returns to work on Tuesday is eligible for one full day of TTD wage compensation with 1 DAFW because he/she missed part of their workday on Friday and the weekend is counted because of the Monday absence.

We excluded cases paid only temporary partial disability (TPD) ( $\sim 5 \%$ of cases) because such cases involve continued employment [Minn. Stat., 2007c] by temporary placement in "light duty" jobs or reduced daily work schedules without DAFW (they would show up in the BLS survey as restricted time cases and would not have had case-specific data collected) and cases with both TPD and permanent partial disability (PPD) ( $0.3 \%$ of cases) or cases paid only PPD (3\%). Some cases with PPD involve payments of 
specified amounts for anatomic/functional loss that require medical care but do not necessarily involve DAFW beyond the waiting period, for example, hearing loss [Minn. Rules, 2007a] or amputation of the distal phalange of the little finger [Minn. Rules, 2007b] requiring medical care on the day of the injury or other permanent functional loss without DAFW.

Individuals where all the payments were in the form of a stipulation or settlement ( $\sim 7 \%$ of cases) were also excluded. This was done because the medical care and wage compensation components were not reported separately in the amount that settled the case. It is possible that any component of wage payments in those with only stipulation payments is for PPD only. These payments are for the loss in future earnings and not lost worktime in the acute period and would not have DAFW in the SOII survey. To distinguish these alternatives, we compared the percent of cases with a First Report of Injury (FROI) [MN DOLI, 2008] and a First Day of Lost Worktime (FDLT) reported in stipulation/ settlement cases with the percent of such cases with TTD payments. Minnesota law requires filing a FROI for injuries that cause death or serious injury within $48 \mathrm{hr}$ of the injury and within 14 days of the FDLT for injuries that prevent a worker from performing labor or service for more than three calendar days [Minn. Stat., 2007d]. Among workers who received TTD payments $(84.3 \%), 73 \%$ had both date of injury and a FDLT while among the almost 9,000 stipulation/ settlement cases (7\%) two-thirds had no FROI or one without an FDLT, while only a third had both a date of injury and a FDLT. The third of cases with no FROI and the third with a FROI but no FDLT suggest settlements for PPD. In addition, the FROI was received within 5 weeks for $71 \%$ of the cases that received TTD compared to only $36 \%$ of the third of the stipulation/settlement cases that submitted a FROI but had no entry for a FDLT value. The late submission of the FROI also supports our decision to exclude stipulation/settlement cases from the analysis.

Data for 2001 presented a special problem. Using the same March 2002 date that we used in the earlier article for 2001 for a data extract in our current article would have ignored the later-filed cases that are reflected in the late-filed long tail. Accordingly, we extracted the number of cases filed through October 2007 that had a date of injury in 2001 (a data extract is taken annually in October for preparing the annual report for the preceding year). The total number of WC cases for the period 1998-2001 used in the present report constitutes $96.6 \%$ of the actual number of cases for this period accepted through July 2008. An analysis of the latefiled cases showed that only $26 \%$ of such cases received any TTD payments, a percent representing $<1 \%$ of all TTD payment cases. Our final study total is within $1 \%$ of the total used by Boden and Ozonoff [2008].

We note two subgroups of reported claims that are not included in the present study either because the insurer denied liability or because, although the claim was for wage compensation and liability was accepted, no wage compensation payment was ever made for time away from work. However, to the extent that claims in either group include "false negatives," that is, they were wrongfully denied, our estimate of concordance in the results between the counts in the BLS SOII survey and the WC system would be affected.

There were $\sim 12,700$ claims over the period 1998-2001 where the insurer denied liability and no payments were ever made because they concluded it was not work related. Gradual hearing loss (presbycusis) and heart attacks, judged to be "ordinary diseases of life" without special occupational circumstances, or injuries that do not "aris[e] out of and in the course of employment" are not covered by WC [Minn. Stat., 2007f]. Approximately 11,000 claims were initially denied but were eventually paid. Future studies would be required to obtain the data necessary to identify and characterize any possible "false negatives" in the group denied coverage and never paid.

In addition, some 7,800 claims for wage compensation were not denied but received no indemnity payments. Their status as accepted claims and a small sample suggest that most such cases did not ultimately have enough lost time days to qualify for wage compensation or that the employee was not medically authorized for disability beyond the waiting period or that light duty was offered the employee but that he/ she declined making them ineligible for TPD payments (TPD payments do not involve full DAFW).

Although it is possible that there could be some "false negatives" in these two subgroups of cases since very few remedial systems have perfect sensitivity and specificity, a future study is required to estimate this fraction precisely.

The complex relation between the various subsets of work injury cases in the SOII and WC data sets are illustrated in Figure 1 which summarizes our methodologic decisions. The figure was prepared using Visio@ $₫$ 2007. For the reasons given in this section, the only directly comparable subsets of the two data sets are those shown in the overlapping portions of the two exploded pie charts and the numbers represented by these overlapping pie slices are the quantities compared in the present article. Although membership criteria for the two databases are different, the overlapping pie slices can be extracted from the two databases as described. While estimating concordance of the number of cases as we do does not reach the gold standard of case-specific matching in capture-recapture methods, it does have the virtues of identifying the maximum number of cases that might be matched by such techniques and, to the extent there are differences in the matchable case numbers in the two databases, providing some evidence of an undercount in one of the systems.

Unfortunately, additional cases for comparison cannot be identified in the non-overlapping pie slices because required data elements in the respective databases are not 


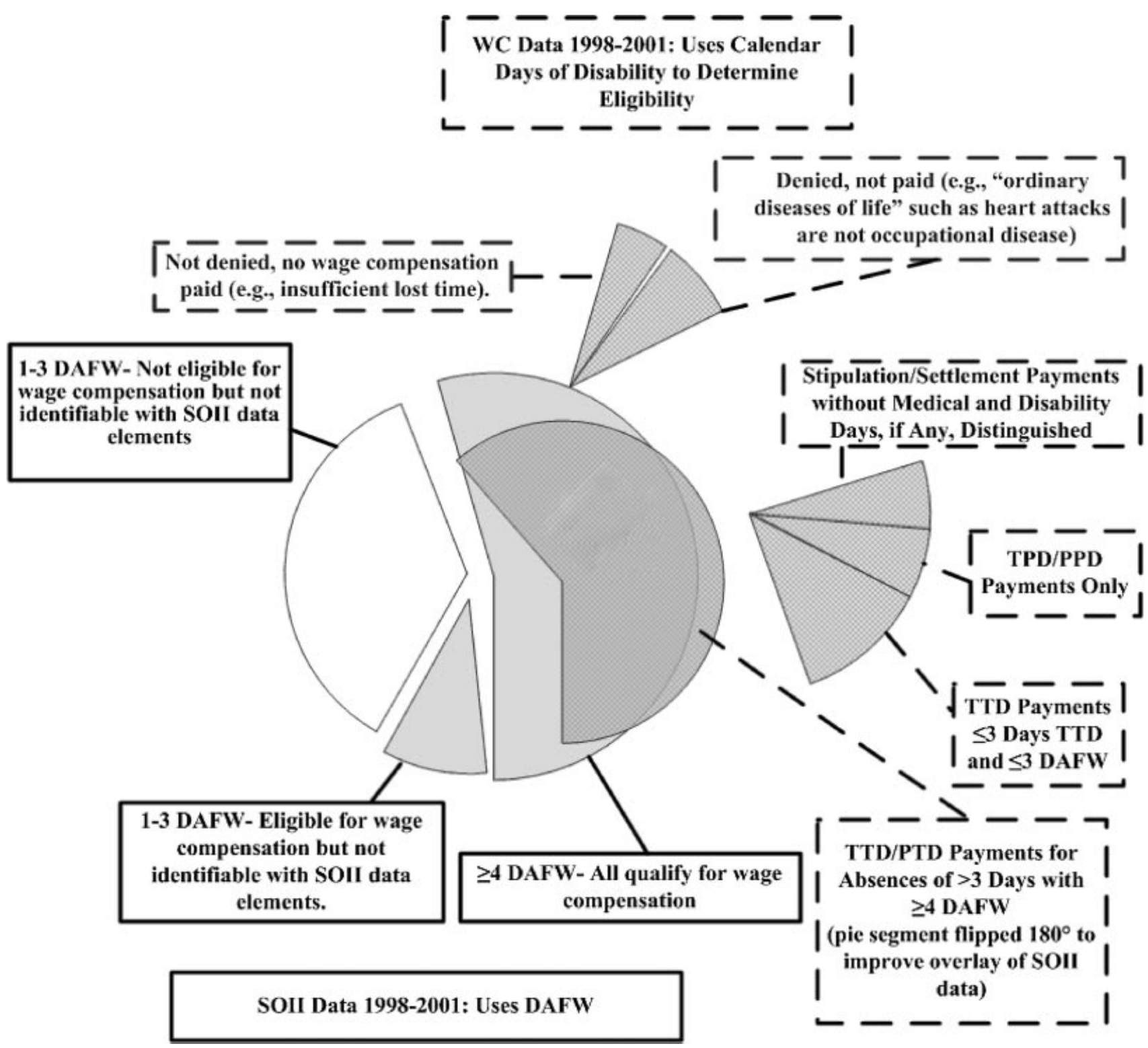

FIGURE 1. Exploded Pie Chart/Venn Diagram to Illustrate the Appropriately Comparable Overlapping Subsets Among Work Injuries Recorded by the BLS SOII (solid line) and the State WC Systems, Minnesota, 1998-2001 (dashed line) (Scale only approximate).

collected. In the discussion concerning legal issues, we conclude that the attempt to do so by Boden and Ozonoff [2008] produces an inflated estimate of the undercount.

It is important to recognize that cases not included in the overlapping sections indicated are not necessarily missed by either system. For example, the SOII cases with 1-3 DAFW that are not eligible for WC may still have been found in the WC cases receiving only medical care payments for their work injuries. Conversely, the WC cases with payments for TPD or PPD only might be included in the SOII cases without DAFW where identifying information is unavailable. A high percent of individual case matching in the two subsets that should match suggests to us that the same would be true for the two complete databases if adequate identifying information were available.

\section{Matching Issues}

To obtain an upper bound estimate on the likelihood of Boden and Ozonoff [2008] matching cases between the Minnesota SOII sample and the state's WC database, we obtained the percent of missing data for selected match elements in the BLS data and then, for the Minnesota WC data, also looked at the correspondence between WC data elements and Minnesota unemployment insurance (UI) information. The Minnesota UI information is ultimately 
forwarded to the BLS and forms the basis for the agency's Longitudinal Data Base (LDB) that is used to create the samples of establishments for the SOII. Boden and Ozonoff [2008] used the LDB in their case-specific matching.

The SOII form contains all the information required for the injured worker - name, date of birth or age, date of injury, and gender. Based on national-level information obtained from the states on employers covered by UI, the BLS LDB can be accessed through the employer number on the survey form. The LDB provides employer name(s), employer address(es), and employer zip code or city which differ if there is more than one establishment within a company.

After discussions, BLS provided the fraction of missing data for employer identifier (UI\#) and federal employer identification number (FEIN) for the corporate or business entity, the separate establishment number, employer name, and employer address with zip from the current cumulative LDB file. For companies consisting of a single establishment, the LDB data are straightforward-a single UI\#, a company legal name, a trade name/Doing Business As (DBA) name, and an address. For companies with more than one place of business or multiple establishments, the data are much more complicated and are obtained from an additional form, the Multiple Worksite Report (MWR) (BLS3020), required by Minnesota of employers [Minn. Stat., 2007e]. This form adds an establishment number (the corporate UI\# plus a suffix for the establishment), a business name for the establishment such as a division name, a physical location address, and a worksite name or description for each establishment, for example, store number. In addition, BLS adds a mailing address (other) that indicates where the survey is to be mailed if it is not to be sent to the physical address. Thus, for each multi-establishment company there are four possible names and three possible addresses for reference. Third quarter 2002 national data indicated $\sim 6.9$ million employers with 8.0 million worksites or establishments in the national UI files [Searson, 2003] that ultimately make up the LDB files. Reconstruction of the database as it existed at the time of the Boden and Ozonoff study was not possible and some of our results may reflect changes in names and addresses associated with ownership changes over time.

On the WC side, we undertook different analyses for the data elements of employer identifier, name, and address. UI\# had been verified or obtained by a special research project covering 1998-2000, subsequently extended to 2001, by matching employee Social Security numbers in the mandatory FROI (required when an employee meets the waiting period for wage compensation with some of its data elements updated generally shortly afterward by the Notice of Insurer's Primary Liability Determination) [MN DOLI, 2008] with the numbers in reports of UI employee wage data from the Minnesota Department of Employment and Economic Development (DEED) and then extracting the DEED UI\# for the employer.
During the period 1998-2001, the FROI also contained spaces for legal name, trade name, and a contact address regarding the claim. In addition, the physical address from the Minnesota UI employer file was provided in the Boden and Ozonoff [2008] FROI extract as a supplement to the contact address. To obtain data on the consistency of names and addresses between the WC FROI and UI databases, we turned to two current databases for comparisons. The first of these is the file of WC claims filed during the period July 1, 2007-June 30, 2008. The second is the current Minnesota UI employer file maintained by the DEED. Once again, it was not possible to reconstruct these two files as of 2002 to account for ownership changes since that time. We calculated the percent of time that the first eight characters in the WC legal name and DBA name matched those in the UI file and the percent of time that the physical addresses matched with both analyses conditional on a match on the UI\#. The matching effort did not adjust for any different syntax rules for entering data in each file.

The study was approved by the University of Michigan Institutional Review Board.

\section{RESULTS}

Table I shows the comparison of counts between the SOII and the WC claims for the same year for private industry and state and local government combined. Exclusion of cases with $\leq 3$ DAFW reduces by almost half the SOII population in the annual data and overall for the period. The total estimated statewide count of SOII cases with $\geq 4$ DAFW, the minimum number of DAFW that assures meeting the WC waiting period, for the period 1998-2001 is in the range of $78,089-83,753(52-56 \%$ of the total number of cases with any DAFW).

For WC cases with wage compensation for DAFW, the total number of cases receiving any type of indemnity for lost wages is 128,563 . After limiting the comparison group to cases receiving TTD and/or PTD payments and taking into account the effect of the calendar counting convention for determining wage payment eligibility by removing the cases compensated for $\leq 3$ days of TTD where the workers also had $\leq 3$ DAFW the total for the period is 93,013 . The adjusted figure of 93,013 is appropriate, in our view, for comparison with the adjusted figure of 78,089-83,752 for the BLS count. The BLS estimate for the entire calendar period of 1998-2001, at the low end of the range, is $84 \%$ of the WC estimate and, at the high end of the range, is $90 \%$ of the WC estimate. It is interesting to note that, with a longer follow-up period in 2001 to allow for the long tail for filing claims, BLS counts $81-88 \%$ as many cases as the WC system. However, this lower fraction may reflect the longer follow-up for this annual cohort and the very high fraction of payments for probable PPD only cases in late-filed cases. 


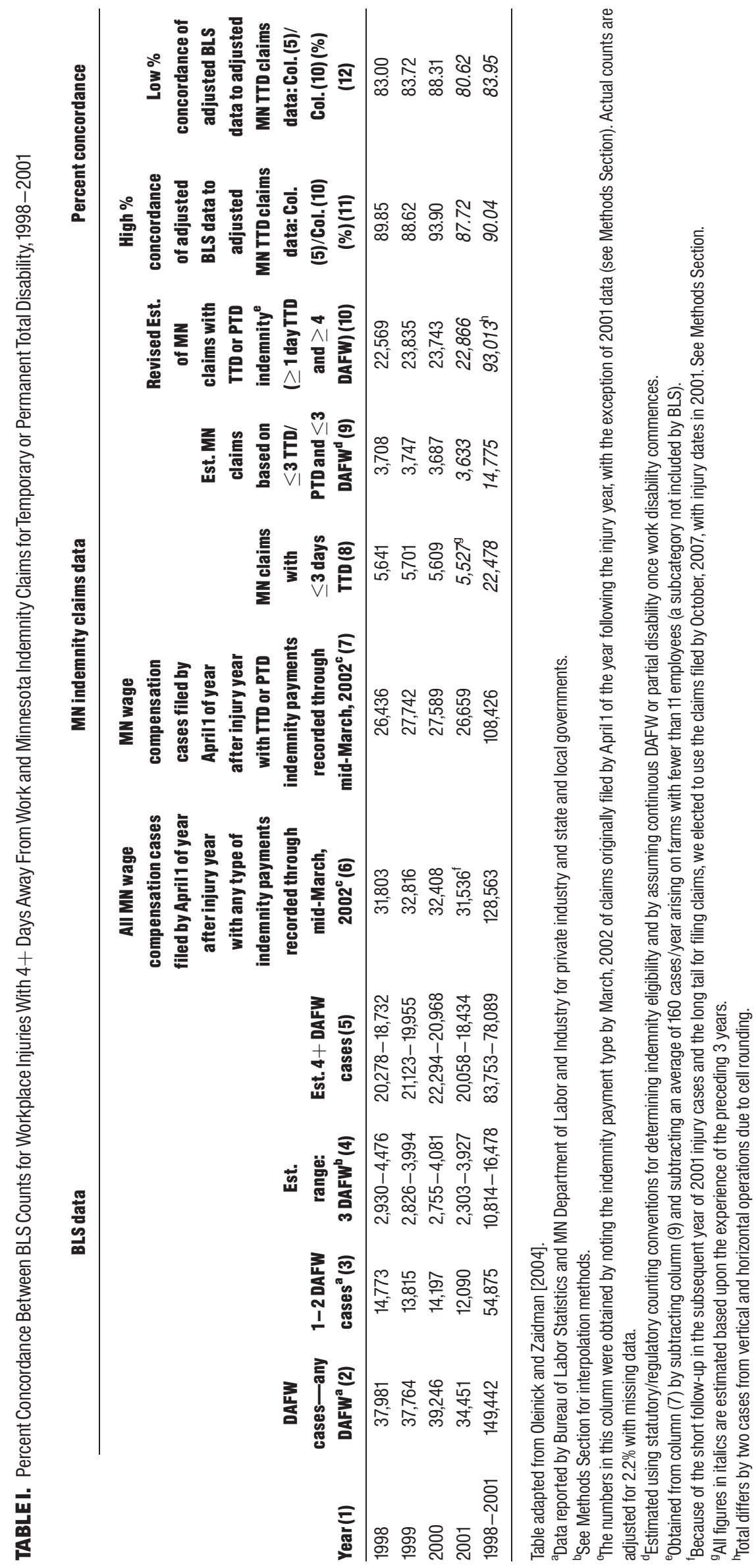


TABLE II. Comparison of Completeness of Reporting of Data Elements in the BLS Longitudinal Database WithThose in the Minnesota Workers' Compensation Database

\begin{tabular}{|c|c|c|c|}
\hline Boden criteria & \multicolumn{2}{|r|}{ Data elements BLS-LDB/WC } & $\begin{array}{l}\text { National BLS_percent missing } \\
\text { Minnesota WC data_-percent matching } \\
\text { between WC and UI files }\end{array}$ \\
\hline Employer identifier & \multicolumn{2}{|r|}{$\begin{array}{l}\text { 1BLS-LDB: Ul/establishment } \\
\text { number (EN) and FEIN; } \\
\text { WC: same }\end{array}$} & $\begin{array}{l}\text { BLS: 0\% UI/FEIN }{ }^{\mathrm{a}} \\
\text { WC:UI \#/year: } 1998-2001 \text { (special run): } \\
11-17 \% \text { FEIN: } 5 \%\end{array}$ \\
\hline Employer name & \multicolumn{2}{|r|}{ 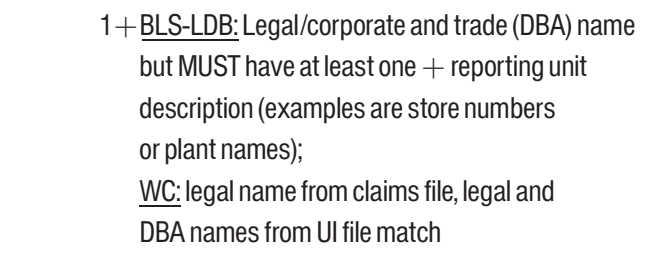 } & $\begin{array}{l}\text { BLS-LDB: legal/trade name/reporting } \\
\text { unit description- } 13 \% / 46 \% / 85 \% \\
\text { WC to DEED: } \\
\text { on a Ul \# match, } 42.3 \% \text { non-matches (first } 8 \text { characters) }\end{array}$ \\
\hline Employer address with zip & $\begin{array}{l}\geq 2 \text { ad } \\
1 \text { zip }\end{array}$ & $\begin{array}{l}\text { ress BLS-LDB: mailing address for } \\
\text { reporting unit and physical address of survey } \\
\text { establishment + Ul address; } \\
\text { WC: mailing address and } \\
\text { physical address_-address used } \\
\text { to contact re. workers' compensation } \\
\text { issues and may not be the legal or } \\
\text { establishment address }\end{array}$ & $\begin{array}{l}\text { BLS-LDB: mail address reporting unit-79\% } \\
\text { mail zip reporting unit-78\% } \\
\text { mail all reporting unit-78\% } \\
\text { physical address-20\% } \\
\text { physical zip-18\% } \\
\text { physical all-17\% } \\
\text { Ul (corporate/legal) address-5\% } \\
\text { Ul zip-4\% } \\
\text { Ul all-4\% } \\
\text { WC to DEED: b,c } \\
\text { WC mail address to Ul physical address, conditional } \\
\text { on UI \# match, 38.9\% non-matches }\end{array}$ \\
\hline Worker's first initial & 1 & Same & \\
\hline Worker's last name & 1 & Same & \\
\hline Sex & 1 & Same & \\
\hline Date of injury & 3 & Same & \\
\hline Date of birth/age & $1+$ & Same & \\
\hline Total & $14+$ & $14+$ & \\
\hline
\end{tabular}

${ }^{\mathrm{a} B L S}$ matches based on current LDB file.

WWC to DEED matches use the 07/01/07-06/30/08 WC file and the and UI employer files current through the last quarter 2007.

${ }^{c}$ Employer mailing address is required for all WC claims. If the physical address is not different, the mailing address is also used for the physical address.

The data also show that the number of cases receiving wage compensation for a total of $\leq 3$ days TTD on the basis of $\leq 3$ DAFW constitute $65.7 \%$ of the number of cases with $\leq 3$ days of TTD. Only some $(20.7-22.5 \%)$ of the cases with $\leq 3$ DAFW received wage compensation compared to the number noted in the SOII data.

Table II gives the percentages missing for the match data elements. For example, the LDB file fields for the UI number, FEIN and the establishment number are $100 \%$ complete, the legal name is missing in $13 \%$ of entries, DBA is missing for $46 \%$ of entries (although one of the two must be present) and a reporting establishment descriptor is missing in $85 \%$ of entries. Similarly, some $17 \%$ of records lack any physical address for the reporting establishment. Four percent of cases lack a UI corporate or business entity mailing addresses.
On the WC side, Table II shows that the special study extract covering 1998-2001 was able, using the injured worker's Social Security number, to identify UI numbers in the Minnesota DEED UI file for employee wages for 83 $89 \%$ of WC cases over the study period (this study used the most current FROI at the extract date in 2002). Where DEED could not provide a UI number, the number provided on the WC form was retained. This occurred $11-17 \%$ over the calendar period 1998-2001. As a result, it is unclear how accurate the several employer variables could then be given no match was found in the DEED UI employee wage file.

A match of what are entered as legal names in the WC and UI current files on the first eight characters, conditional upon a match of the WC and DEED files on the UI\#, showed a name match in $57.7 \%$ of cases. 
A match of addresses in both current databases showed that matches between the first eight characters of the WC mail address and the UI physical address were present in $61.3 \%$ of cases, again conditional upon a match of the UI\# in the WC and DEED files.

\section{DISCUSSION}

In a 1993 article Oleinick et al. [1993] reported that the BLS annual survey of DAFW cases, using 1986 Michigan data from the Supplementary Data System (SDS) based upon FROI submitted to state WC agencies which then provided the SOII DAFW data, substantially underestimated the duration of disability for work injuries in the private sector. Using data from the Michigan SDS and WC systems we estimated that 1986 work injuries nationally produced 420 million missed workdays compared to the BLS estimate of 47 million. The present SOII sample methodology is based upon a revision that took effect in 1992, retaining the SDS survey reporting deadlines but substituting the national SOII survey.

We suggested that BLS' underestimate of the chronic burden imposed by work injuries and illnesses in the SDS was the product of a difficult trade-off. This trade-off entailed doing the survey soon enough after the injury year to assure that records and memories would be routinely available while waiting long enough that an accurate estimate of the long-term disability might be obtained. Clearly, conducting the survey with deadlines in the second quarter following the injury year was too soon to get accurate long-term disability data although the present practice of truncating DAFW at $31+$ days should allow for analysis of DAFW groupings as a proxy for severity.

Since the SDS and WC counts were based on the same form, SDS sensitivity could not be evaluated because the counts were not independent. However, the present SOII and WC counts are obtained independently. In the present article, the concordance range of the SOII with the comparable WC count for the overall study period 1998 2001 of $84-90 \%$ is lower than the range for the interval $1992-2000$ of $87-93 \%$ in the earlier article and may indicate a downward drift in reporting SOII DAFW cases. Nonetheless, even with this lowered concordance rate, we continue to believe that select WC databases are appropriate for epidemiologic studies, particularly of the more severe injuries.

The recent reports by Rosenman et al. [2006] and Boden and Ozonoff [2008] using case-specific information and capture-recapture methods challenge the accuracy of the BLS count itself. We believe that their failure to incorporate fully the law as a confounder results in "false positives" in both the SOII and WC databases that cannot be matched. Whether one characterizes the problem as one involving the creation of comparable databases by adjusting for differences produced by WC law or, in a more formal description, as a capture-recapture study employing sources with falsepositive and false-negative cases in one [Brenner, 1996] or both of two sources, the failure to fully incorporate the law as a confounder results in biased estimates.

\section{The Effect of Legal Issues}

Rosenman et al. [2006] reported that the BLS SOII matched 39\% of the total number of Michigan cases present in the combined number of unique cases using case-specific data from both BLS and WC databases. Moreover, this percent reduced to $32 \%$ after the capture-recapture method was used to estimate the number of cases unreported in either database. This remarkably low percent is the result of several methodologic decisions that we believe are arguable. First, he relied on an assertion, by someone or some group at the Michigan Bureau of WC (BWC), that $75 \%$ of cases initiated by a Form 104 (Notice of Mediation) or a Form 107 (Notice of Dispute), but without a Form 100-Report of Injury - in the file, were for injuries/illnesses with "at least 7 consecutive (missed) days" and included them as cases without providing any corroboration that they were bona fide claims.

However, the subsequent payment history for claim filings initiated with no F100 in the file, that is, with only a F104 or a F107, indicates that these groups contain only a small fraction of claims ultimately awarded payments for wage compensation. For the 1993 report Oleinick et al. [1993] used claims with injury dates in 1986 with outcome information in the form of detailed compensation payment information for $31 / 2$ years. There were a total of 90,926 cases where the injury was claimed to have occurred in 1986. Of these, 16,734 cases had either a Form 104 or a Form 107, but no F100. Less than a quarter of this group received wage compensation payments for DAFW through March 1, 1990. Moreover, the WC agency itself did not classify these cases as claims either in their annual reports [BWDC, 2003] or by reporting them to the SDS for use in the BLS SOII [Oleinick et al., 1991]. In contrast, in 1986, only $8.3 \%$ of the 72,823 cases initiated with an F100 showed no payment or duration of paid wage compensation data through the follow-up date [Oleinick, 1991]. In the Rosenman et al. [2006] article, use of the 1986 experience suggests that several thousand cases may represent false positives. It is difficult to be more precise since the actual and estimated statewide totals for cases for which F100s are required differ substantially (exclusive of the capture-recapture estimate for cases not present in either database).

There are, of course, several reasons why a claim may not progress to actual wage payments - the insurer may have forgotten to forward the required payment forms to the Michigan agency (although this possibility seems unlikely for mandated reporting involving $20 \%$ of submitted cases, 
particularly in the absence of any data to support such a conclusion), the actual days of disability may not meet the waiting period or the injury/illness may not turn out to be work related for a variety of reasons.

In addition to his decision regarding cases with only a F104 or F107, we believe a third source of false positives is the product of the calendar counting convention used in Michigan to determine eligibility for wage compensation [Mich. Admin. Code, 2008; Mich. Comp. Laws, 2008a]. Wage compensation payments in Michigan begin on the eighth day after an injury, including Saturday and Sunday in the count as long as work disability is present on either side of the unscheduled worktime, provided the worker is incapacitated for 7 consecutive days. Like Minnesota, the interval is calendar time, not DAFW. Thus, Rosenman et al.'s [2006] use of BLS cases "with greater than 7 DAFW" in the BLS file to match against the WC file precluded matching a number of $\mathrm{WC}$ cases that received 1-2 days wage compensation with 6-7 DAFW. The restriction of BLS cases for matching again creates false positives in the WC group. The magnitude of this effect is unknown, but with a shorter waiting period in Minnesota it was large.

Boden and Ozonoff [2008], also using capturerecapture methods and with some adjustments in both databases for the period 1998-2001 for six states including Minnesota, reported that the WC data for Minnesota matched $68 \%$ of cases found by the BLS survey while BLS matched $65 \%$ of cases in the WC database (again exclusive of the capture-recapture estimate for cases not present in either database). In matching cases, Boden excluded cases arising in temporary employment agencies, which includes temporary help services, professional employer organizations and employee leasing services. These agencies often report worker compensation cases to state agencies under their own name. The OSHA record-keeping requirements, however, place responsibility on the employer at the work establishment for recording occupational injury and illness data in the establishment log [Letter of Interpretation, 2003] so that the case generally shows up under a different employer than the WC case.

Commercial enterprises of recognized tribal entities comprise another source of establishments what will often result in non-matches. Prior to 2003, these establishments were included in the private sector LDB. In Minnesota, these tribal entities, with combined employment of over 15,000 workers in 2000 [Hillman and Tietma, 2002], may or may not have participated in the state's WC system and may have declined to participate in the BLS survey.

The effect of the difference between Boden and Ozonoff's methods [2008] and our own is perhaps most easily seen by working backward from published statewide SOII estimated counts and the actual counts for filed WC Minnesota cases to try to confirm the estimated 117,154 SOII cases statewide that Boden and Ozonoff reported as eligible for matching to the WC cases. In annual reports, the BLS SOII reported an estimate of 132,312 DAFW cases originating in private industry during the period 19982001 (http://www.bls.gov/iif/ oshstate.htm). This estimate included some 5,200 cases from industries that Boden and Ozonoff later excluded from the SOII database because, inter-alia, their information was obtained from other government agencies and not through the sample. This would have left $\sim 127,000$ cases for matching so that would mean that Boden and Ozonoff [2008] excluded an estimated 10,000 cases from the BLS total with the software they used to arrive at their figure of 117,154 estimated reported SOII cases eligible for wage compensation and matching with the Minnesota wage compensation group.

However, we believe that their software necessarily overestimated the number of SOII cases appropriate for matching and this is reflected in the large number of unmatched cases. This is because the SOII forms for Minnesota contain only the date of injury. However, as we showed in our 2004 article for all cases receiving TTD [Oleinick and Zaidman, 2004], and have confirmed for the $\sim 27,000$ wage compensation cases receiving $\leq 3$ days TTD payments noted in Table I, only about a third of wage compensation cases leave work on the day of injury. Another third completes their work shift and their lost worktime begins the next day. For the final third of cases the FDLT begins on the 2 nd day after the date of injury or later. This injury sequence is particularly true for musculoskeletal injuries where a failure to ice the injury in the immediate post-injury period may produce a clinical worsening by the next morning.

Thus, software that has available only the day of injury, and not the first day of any lost worktime, starts the count for wage compensation eligibility too soon and results in overestimation of total cases eligible for matching. Given that the BLS SOII estimated that there were $\sim 55,000$ cases with 1-2 DAFW while we estimated that there were an additional $\sim 13,000$ cases with 3 DAFW (in the 3-5 DAFW group) and that we found $\sim 15,000$ in this group had actually received wage compensation, the software flaw we identify would likely result in thousands of "false-positive" cases in the estimated unmatched reported SOII group.

Boden and Ozonoff's figure for the reported number of Minnesota WC cases for comparison with the BLS SOII cases similarly appears too high at 112,251 . This number is an estimate, not an actual count, and is based on two assumptions: first, that the risk of a WC case in the sampled establishment applies to all the firm's employees so that the number of cases in the parent firm is inversely proportional to the fraction of firm employees in the establishment and, second, that the BLS sampling weights for DAFW cases apply to WC cases. While we are sympathetic to the 
claim that these assumptions were required because they dealt with a sample, the fact remains that there is an actual count of WC cases for the period. The count, excluding state/local government cases and cases from industries excluded by Boden and Ozonoff is just under 100,000 (cases paid for TTD/PTD and stipulated/settled cases, excluding state/local government and excluded industry cases). We estimate that later-filed cases would increase this number by only about $1 \%$. Moreover, this number includes some 8,000 stipulated/settled cases and we have already noted that there is no file evidence of DAFW in about $2 / 3$ rds of such cases, suggesting that many of them represent payments for PPD without DAFW. Since the error in the estimate disproportionately affects the unmatched cases, use of their estimate for total cases results in an overestimate of the undercount.

The state of research involving matching cases in the two databases can thus be summarized as follows: The present study finds reasonable concordance between the total numbers of comparable cases in each database (range 84-90\%) after adjustment to restrict the comparison to cases in each group with $\geq 4 \mathrm{DAFW}$. Adding in the stipulation cases that may include TTD payment would shift this range down as much as $2 \%$. Adding in the later-filed cases probably receiving TTD payments would shift the range down another $1 \%$. While we were unable to match specific cases in the two groups, and it is thus theoretically possible that the two groups are actually completely discordant, the fact that Boden and Ozonoff [2008] were able to match 75,916 cases from these same databases (although this figure may include some cases we excluded) suggests that our concordance estimates are reasonable and suggest a more moderate undercount by the SOII than the 32\% they reported. Therefore, we believe that the estimates of matching by both Boden and Ozonoff [2008] and Rosenman et al. [2006] underestimate the true overlap between the two comparable subsets in the larger databases because both investigators appear to include many thousands of cases as non-matches that are, in effect, false positives with respect to the capturerecapture methodology.

The need to correct for different definitions of cases in the BLS and WC systems is a general one; in addition to Minnesota, at least three other states used in the Boden and Ozonoff [2008] report-Oregon [Or. Rev. Stat., 2007], Washington [Wash. Rev. Code, 2008] and Wisconsin [Wis. Stat., 2007] —use calendar period to determine wage compensation eligibility and there is variation in how weekend days are treated.

\section{The Effect of Matching Criteria}

The ability to detect matches between one database nested within, or overlapping, a second database depends on at least three intrinsic qualities of the matching criteria. These are: the number of criteria required for a match, the frequency of missing data for the matching criteria and the similarity or syntax of information entry for the data elements to be matched. The tabulation of percentages of missing data in the BLS LDB, the 11-17\% fraction of UI\# in the Boden extract that could not be verified originally through the Minnesota employee wage file (in part because some out-of-state workers received WC in Minnesota while the employee wage data was entered in the firm's home state UI file) and the high percent of non-matches we found between the current Minnesota WC and UI employer files when matches are attempted between various categories of names and addresses suggest that at least some of the mismatches between the Minnesota WC file and the BLS survey result file may reflect the effect of decisions on matching criteria. This is particularly true for the first deterministic matching stage used by Boden and Ozonoff [2008] where the article specified that exact matches were required on eight of nine variables: employer identifier, employer name, employer address, employer zip code or city, worker's first initial, worker's last name, sex, date of injury, and date of birth or age. As noted in Table II, these nine variables actually deconstruct to 9-14 variables, depending on how the data is entered.

However, despite what appears to be very strict matching criteria in light of several reports in the literature indicating match acceptance with 7-8 deconstructed data elements [Merrill et al., 2003; Merrill, 2004; Merrill and Folsom, 2005; Clements et al., 2006], this step yielded Boden a match for 75,916 cases, $\sim 65 \%$ of the cases in both the BLS and WC databases. Moreover, $90-95 \%$ of matched cases were produced by matching at this first step. All decreases in the number of matching criteria produced only an additional $5-10 \%$ of matched cases.

The high number of matches in the first matching step could reflect a high rate of matches for single establishment companies where there are single names and addresses as well as the fact that the WC first injury report is acceptable for the purposes of reporting to the BLS survey [OSHD, 2007]. In the third quarter of 2002, Searson [2003] reported that single-establishment employers represented about $98 \%$ of total employers, controlled $85 \%$ of worksites and were responsible for $62 \%$ of the country's non-farm employment. The $62 \%$ figure is sufficiently similar to the fraction matched in the first step and the fractions matched reported in our Table II as to raise the hypothesis of disproportionate representation of single company establishments in the matched group. Nestoriak and Pierce [2009] identified single and multi-establishment firms in Wisconsin, using BLS SOII and WC data and the Boden and Ozonoff [2008] data sets including the matched case subgroup. They found that the SOII matched/captured $77.5 \%$ of single establishment cases in the combined SOII and WC databases but only $62.2 \%$ of cases from the multi-establishment firms. Unfortunately, 
neither the precise matching algorithm nor the precise adjustments for sampled establishments from multi-establishment firms with results at each step were presented in the Boden and Ozonoff [2008] article.

Neither the precise matching algorithm nor the quantitative results at particular steps are presented by Rosenman et al. [2006]. It is, therefore, unclear whether incomplete or variant information in the databases was responsible, in part, for their matching failures.

\section{Other Studies}

A number of other studies have been cited in support of the proposition that BLS and WC systems undercount work injuries and illnesses. However, four of them [Fine et al., 1986; Eisenberg and McDonald, 1988; Seligman et al., 1988; McCurdy et al., 1991] use data from 1986 or earlier, while one covers the period 1986 to mid-1989 [Silverstein et al., 1997]. The calendar period is important because in the late 1980s a series of record fines were levied against the Big Three auto makers [Associated Press, 1987c,b; Cole, 1987] and corporations in other industries [Shabecoff, 1987; Associated Press, 1987a,d] for poor injury/ illness record-keeping. The one study [Silverstein et al., 1997] from this period to report both before and after statistics showed a marked increase in the ratio of BLS to WC cases in the year following the auto industry fines. Thus, the relevance of these early studies to the current debate is arguable.

Two recent reviews [Azaroff et al., 2002; NASI et al., 2009] include a number of more recent studies that document underreporting of work injuries and illnesses but, with the exception of the studies cited below, the cited studies either do not incorporate the law as a confounding variable in ascertainment and/or do not provide a basis for estimating undercounting at the state or national level.

Two studies conclude that SOII undercounts workplace injuries on the basis of a comparison of state injury rates for construction workers with nationwide rates for workers in the construction industry [Glazner et al., 1998 (Colorado); Lipscomb et al., 2008 (Washington)]. However, it is not clear that the appropriate comparison rate is the national one. State rate information is available online from BLS for Washington [BLS, 2003] but not Colorado. Instead of the comparison Lipscomb used (3.8 back, back and neck and trunk injuries per 100 full-time carpenters v. 6.8 all injuries and illnesses per 100 full-time construction industry workers in the US), the state comparison would be 3.8 back injuries v. 11.1 injuries/illnesses. When one considers that the Lipscomb estimate is increased by about $15 \%$ by the use of medical diagnostic information (unavailable to SOII and resulting in changes in the percent of part of body injured), the percent of back injuries (29.1\%) does not seem very different from the $24.7 \%$ reported for back only injuries for 2004 [2003 unavailable on line; DLI, 2004].

Two other databases have been used to estimate the number of occupational injuries for comparison with the BLS SOII. A study by Smith et al. [2005] used data from the 1997-1999 years from the National Health Interview Survey (NHIS), a survey conducted annually by the National Center for Health Statistics [Blackwell and Tonthat, 2002]. Work injury cases in this study were limited to those that occurred "while working at a paid job" for which the worker sought medical advice or treatment. Using sampling weights for 1,422 work injury cases to extrapolate their results nationally and adjusting for the differences in the sampling frame for the two surveys, the study estimated that there was an average of 2.36 million DAFW injury cases in 1998 in private industry compared to BLS' estimate of 1.649 million cases for the same year, also in employees in private industry, indicating a $30 \%$ undercount.

Despite an apparent difference in the definition of a work injury between the 1988 and 1998 NHIS survey questionnaires, a review of historical material indicates that the change did not greatly affect the definition of a work injury. Between 1988 [Park et al., 1993] and 1998 [Blackwell and Tonthat, 2002], NHIS changed its definition of a work injury from one that tracked the OSHA log definition [29 CFR, 2008] that forms the basis for the SOII to one that counted only those events where the injured worker obtained medical advice (by phone or in person) for the injury. However, a review of the unadjusted 1988 data [National Center for Health Statistics, 1988] indicated that $88 \%$ of individuals reporting a work injury actually saw a medical person (phone contact was not recorded).

Although the DAFW estimate is higher, Smith et al.'s overall annual work injury rate of 4.5/100 employed civilian population is lower than the overall SOII rate of 6.2/100 fulltime private industry employees in 1998 [BLS, 1999]. This is true even after adjustment for loss of information due to the 3-month recall period [Warner et al., 2005] and conversion to a full-time equivalent basis [BLS, 1999]. Thus, the issue may be one of severity classification rather than undercounting. While Smith et al.'s finding suggests that the SOII is once again underestimating severity, our SOII to WC comparison suggests that the severity underestimate is not as great as Smith suggests. This issue could be resolved by using casespecific information for all three databases.

A fourth database has been used to estimate the number of annual work injuries [Division of Safety Research, 1998]. This is the National Electronic Injury Surveillance System (NEISS) developed by the federal Consumer Product Safety Commission. In an article providing a summary of 1998 data [Division of Safety Research, 2001] the authors estimated the number of occupational injuries and illnesses at $\sim 10 \times 10^{6}$ using their national estimate of $3.6 \times 10^{6}$ work injuries and illnesses first treated in emergency departments. To 
extrapolate to a national estimate of all work injuries and illnesses, they used the figure of $34 \%$ from the 1988 NHIS occupational health supplement [National Center for Health Statistics, 1988] indicating that this percent of work injuries were seen first in an emergency department. It does not seem possible at this time to reconcile the much larger NIESS national estimate with that obtained by BLS or NHIS (there is no national estimate available for WC cases).

The issue of the percent completeness of reporting of work-related diseases as separate groups to both the SOII and WC systems is beyond the scope of the present article.

\section{CONCLUSIONS}

Both the SOII and WC databases play an important role in evaluating the effectiveness of the laws they track. While our data suggest that the undercount is moderate and the capture-recapture studies suggest that it is much larger, a preferable study design would use capture-recapture methods with closer attention to the confounding effect of legal and database issues. A more definitive study is needed before any total redesign or modification of the present SOII is undertaken since it is not clear at this time just where the troubled areas are. In the planning of such a study, an effort should be made to further harmonize the SOII and WC databases with the NHIS and NIESS databases since the harmonization effort may yield information that could be incorporated into any survey revision. In view of the complexity of the effort, it would be helpful if BLS would convene an expert panel to help plan any further studies.

\section{ACKNOWLEDGMENTS}

We wish to thank William McCarthy (retired), Chief, Division of Safety and Health Statistics, Office of Safety, Health and Working Conditions, Bureau of Labor Statistics, Department of Labor, for providing data that we requested on the completeness of information for selected data elements in the Bureau's Longitudinal Database.

\section{REFERENCES}

Associated Press. (July 30, 1987a). General Dynamics is fined by U.S. safety agency. The New York Times. URL: http://query.nytimes.com/ gst/fullpage.html?res=9B0DE0D8163EF933A05754C0A961948260 $\&$ scp $=1 \&$ sq $=$ General $\% 20$ Dynamic $\% 201987 \% 20$ fined $\&$ st $=$ cse NYT 7/30/87 (ship building).

Associated Press. (November 11, 1987b). Ford is penalized $\$ 325,000$. The New York Times. URL: http://query.nytimes.com/gst/fullpage. html?res=9B0DE1DF113AF932A25752C1A961948260\&scp=1\&sq $=$ Ford $\% 201987 \% 20 \% 24325,000 \& s t=$ cse $($ Ford $)$.

Associated Press. (October 6, 1987c). GM to pay big OSHA fine. The New York Times. URL: http://query.nytimes.com/gst/fullpage.html? res $=9$ B0DE7D 7103FF935A35753C1A961948260\& $\mathrm{scp}=16 \& \mathrm{sq}=$ OSHA\% $201987 \&$ st $=$ cse $(\mathrm{GM})$.
Associated Press. (September 26, 1987d). Scott Paper to pay fine for safety violations. The New York Times. URL: http://query.nytimes. com/gst/fullpage.html?res=9B0DE2D8153EF934A35751C1A961948 260\&scp $=2 \&$ sq $=$ Scott\%20Paper\%20Injury\%201987\&st=cse（paper making).

Azaroff LS, Levenstein C, Wegman DH. 2002. Occupational injury and illness surveillance: Conceptual filters explain underreporting. Am J Public Health 92(9):1421-1429.

Blackwell DL, Tonthat L. 2002. Summary health statistics for the U.S. population: National Health Interview Survey, 1998. National Center for Health Statistics. Vital Health Stat Series 10, 207:1-93.

Boden LI, Ozonoff AL. 2008. Capture-recapture estimates of nonfatal workplace injuries and illnesses. Ann Epidemiol 18(6):500-506.

Brenner H. 1996. Effects of misdiagnoses on disease monitoring with capture-recapture methods. J Clin Epidemiol 49(11):1303-1307.

Bureau of Labor Statistics (BLS). 1999. Workplace injuries and illnesses in 1998. URL: http://www.bls.gov/iif/oshwc/osh/os/ osnr0016.pdf (additional years in the study interval also available on the BLS site).

Bureau of Labor Statistics (BLS). 2000. Lost-worktime injuries and illnesses: Characteristics and resulting time away from work, 1998. http://www.bls.gov/iif/oshwc/osh/case/osnr0010.pdf (additional years in the study interval also available on BLS site).

Bureau of Labor Statistics (BLS). 2003. Table 6. Incidence rates of nonfatal occupational injuries and illnesses by industry and case type, 2003. URL: http://www.bls.gov/iif/osh/os/pr036wa.pdf

Bureau of Workers' and Unemployment Compensation (BWDC). 2003 Michigan Workers' Compensation 2002 Annual Report. URL: www.michigan.gov/documents/wca_02_annrpt_78927_7.pdf

29 C[ode of] $\mathrm{F}$ [ederal] R[egulations] (CFR) § 1904.7., 2008 http://www.osha.gov/pls/oshaweb/owadisp.show_document?p_table= STANDARDS\&p_id $=9638$

Clements KM, Barfield WD, Kotelchuck M, Lee KG, Wilber N. 2006. Birth Characteristics Associated with Early Intervention Referral, Evaluation for Eligibility, and Program Eligibility in the First Year of Life. Matern Child Health J 10:433-441.

Cole KB. (January 31, 1987). Chrysler will pay $\$ 295,000$ fine for violations of injury records. The New York Times. URL: http:// query.nytimes.com/gst/fullpage.html?res=9B0DE3D91E38F932A05752 C0A961948260\&scp $=1 \&$ sq $=$ Noble $\% 20 \% 24295,000 \% 20$ Chrysler \& $\mathrm{st}=\mathrm{cse}$ (Chrysler).

Division of Safety Research. National Institute of Occupational Safety and Health. 1998. Surveillance for nonfatal occupational injuries treated in hospital emergency departments-United States1996. Morb Mortal Wkly Rep 47(15):302-306.

Division of Safety Research. National Institute of Occupational Safety and Health. 2001. Nonfatal occupational injuries and illnesses treated in hospital emergency departments-United States1998. Morb Mortal Wkly Rep 50(16):313-317.

Eisenberg WM, McDonald H. 1988. Evaluating workplace injury and illness records; testing a procedure. Mon Labor Rev 111(4):58-60.

Fine LJ, Silverstein BA, Armstrong TJ, Anderson CA, Sugano DS. 1986. Detection of cumulative trauma disorders of upper extremities in the workplace. J Occup Med 28(8):674-678.

Glazner JE, Borgerding J, Lowery JT, Bondy J, Mueller KL, Kreiss K. 1998. Construction injury rates may exceed national estimates: Evidence from the construction of Denver International Airport. Am $\mathrm{J}$ Ind Med 34:105-112.

Hillman R, Tietma A. 2002. Casino Gaming in Minnesota-A Winning Job Generator. Minnesota Economic Trends; July/August. 
Minnesota Department of Employment and Economic Development http://www.deed.state.mn.us/lmi/publications/trends/0802/casino. htm

Jansson A, Arneborn M, Ekdahl K. 2005. Sensitivity of the Swedish statutory surveillance system for communicable diseases 1998-2002, assessed by the capture-recapture method. Epidemiol Infect 133:401407.

Letter of interpretation related to sections. 2003. 1904. 29, 1904.29(a),1904.29(b),1904.29(b)(2),1904.31,1904.33,1904.35,1904.40 and 1904.46-Recording criteria for cases involving workers from a temporary help service, employee leasing service, or personnel supply service. Mr. Edwin G. Foulke, Jr 06/23/2003 URL: www.osha.gov/ recordkeeping/handbook/index.htm

Lipscomb HJ, Cameron W, Silverstein B. 2008. Back injuries among union carpenters in Washington State, 1989-2003. Am J Ind Med 51: $463-474$.

McCurdy SA, Schenker MB, Samuels SJ. 1991. Reporting of occupational injury and illness in the semiconductor manufacturing industry. Am J Public Health 81(1):85-89.

Merrill RM. 2004. Life expectancy among LDS and non-LDS in Utah. Demogr Res 10(3):61-82.

Merrill RM, Folsom JA. 2005. Female breast cancer incidence and survival in Utah according to religious preference, 1985-1999. BMC Cancer 5:49-58.

Merrill RM, Hilton SC, Wiggins CL, Sturgeon JD. 2003. Toward a better understanding of the comparatively high prostate cancer incidence in Utah. BMC Cancer 3:14-20.

Mich. Admin[istrative]. Code R 2008. 408.31(1)(1).

Mich. Comp[iled]. Laws. 2008a. \$418.311

Mich. Comp[iled]. Laws. 2008b. §418.361(2).

Minn. R[ules]. 2007a. 5223.0040

Minn. R[ules]. 2007b. 5223.0080

Minn. Stat[utes]. 2007a. §176.121

Minn. Stat[utes]. 2007b. §176.101(5).

Minn. Stat[utes]. 2007c. §176.101(2)(b).

Minn. Stat[utes]. 2007d. §176.231(1).

Minn. Stat[utes]. 2007e. § 268.044(1).

Minn. Stat[utes]. 2007f. §176.011(15),(16).

Minnesota Department of Labor and Industry (MN DOLI). Workers' Compensation Division. Workers' compensation forms. URL: http:// www.dli.mn.gov/WC/Wcforms.asp

National Academy of Social Insurance (NASI). 2009. Workers' compensation: Benefits, Coverage and Costs, 2007. Washington, DC: NASI.

National Center for Health Statistics. Available at ftp://ftp.cdc.gov/ pub/Health_Statistics/NCHS/Dataset_Documentation/NHIS/1988/ OCHEALTH.PDF

Nestoriak N, Pierce B. 2009. Comparing workers' compensation claims with establishments' responses to the SOII. Monthly Labor Review 132(5):57-64.

Occupational Safety and Health Division (OSHD). 2007. Minnesota OSHA recordkeeping requirements (effective Jan. 1, 2002, with revisions effective Jan. 1, 2003 and Jan. 1 2004) § 1904. 29 Forms (WC FROI equivalent reporting form) injury. Minnesota Department of Labor and Industry.

Oleinick A, Zaidman B. 2004. Methodologic issues in the use of workers' compensation databases for the study of work injuries with days away from work. I. Sensitivity of case ascertainment. Am J Ind Med 45:260-274.

Oleinick A, Guire KE, Hawthorne VM, Schork MA, Gluck JV, Alcser K, Lee B, La S, Gentry C. 1991. Final Contract Report. The 1986 Michigan comprehensive compensable occupational injury and illness database. Contract \# 90-20023. Ann Arbor, Michigan. April 8, 1991 .

Oleinick A, Guire KE, Hawthorne VM, Schork A, Gluck JV, Lee B. 1993. Current methods of estimating severity for occupational injuries and illnesses: Data from the 1986 Michigan comprehensive compensable injury and illness database. Am J Ind Med 23:231-252.

Or. Rev[ised]. Stat[utes]. 2007. § 656.210(3).

Park CH, Wagener DK, Winn DM, Pierce JP. 1993. Health conditions among the currently employed, 1988. National Center for Health Statistics. Vital Health Stat Series 10, 186:1-67.

Rosenman KD, Kalush A, Reilly MJ, Gardiner JC, Reeves M, Luo Z. 2006. How much work-related injury and illness is missed by the current national surveillance system? J Occup Environ Med 48(4):357-365.

Searson MA. Web Collection for the Covered Employment and Wages (CEW) Program. 2003. Entire paper at URL: http://www.bls.gov/osmr/ pdf/st030110.pdf

Seligman PJ, Sieber WK, Pedersen DH, Sundin DS, Frazier TM. 1988. Compliance with OSHA record-keeping requirements. Am J Public Health 78(9):1218-1219.

Shabecoff P. (July 22, 1987). OSHA seeks \$2.59 million fine for meatpacker's injury reports. The New York Times. URL: http:// query.nytimes.com/gst/fullpage.html?res=9B0DEFDA153DF931A 15754 C0A $961948260 \& \mathrm{scp}=1 \& \mathrm{sq}=$ Shabecoff $\% 20$ OSHA $\% 20 \%$ $242.59 \& \mathrm{st}=\mathrm{cse}$ (meatpacking).

Silverstein BA, Stetson DS, Keyserling WM, Fine LJ. 1997. Workrelated musculoskeletal disorders: Comparison of data sources for surveillance. Am J Ind Med 31:600-608.

Smith GS, Wellman HM, Sorock GS, Warner M, Courtney TK, Pransky GS, Fingerhut LA. 2005. Injuries at work in the US adult population. Contributions to the total injury burden. Am J Public Health 95(7): $1213-1219$

29 U[nited] S[tates] C[ode] (USC). §657(c)(2) (2000, suppl 5), 2000a. http://frwebgate5.access.gpo.gov/cgi-bin/TEXTgate.cgi?WAISdocID= $854465196099+0+1+0 \&$ WAISaction $=$ retrieve.

33 U[nited] S[tates] C[ode] $\$ 901$ et seq. (USC)(2000 suppl 5), 2000b. URL: http://frwebgate3.access.gpo.gov/cgi-bin/TEXTgate.cgi? WAISdocID $=9304967014+0+1+0 \&$ WAISaction $=$ retrieve .

Warner N, Schenker N, Heinen MA, Fingerhut LA. 2005. The effects of recall on reporting injury and poisoning episodes in the National Health Interview Survey. Inj Prev 11:282-287.

Washington Department of Labor \& Industries (DLI). 2004. Table 5. Number of nonfatal injuries and illnesses involving days away from work by selected injury or illness characteristics and major industry sector, 2004. (No longer available on line, contact WA DLI.).

Wash. Rev[ised]. Code (WRC). 2008. §51.32.090(5).

Wis. Stat[utes] (WS). 2007. §102.43 